\section{Lunar Tide in the Atmosphere}

THE Meteorological Magazine of December 1939 contains a summary by Prof. S. Chapman of his presidential address to the Association for Meteorology at the Washington Assembly of the International Union for Geodesy and Geophysics last September, the subject being the lunar tide in the atmosphere. The author describes the difficulty that was met when the detection of this lunar tide, achieved first by Lefroy in 1842 for St. Helena, was attempted for higher latitudes, which resulted in a succession of failures that was not broken until his own determination in 1918 of the very small Greenwich air tide, from sixty-four years of hourly data. From that year, when the tide was known for three tropical stations and one non-tropical, progress was rapid, and the rate of determination by Prof. Chapman and his assistants was increased threefold in 1930 through a loan of Hollerith machines by the British Tabulating Machine Co. Now the tide has been determined for more than fifty places.

With this number of determinations available for study of the world distribution of phase and amplitude, several interesting peculiarities have come to light; for example, an early maximum is shown at Salt Lake City, San Diego and San Francisco, this being two hours before the upper and lower lunar transits at the last two places, but at the neighbouring high-level stations of Mount Wilson Observatory and Mount Hamilton (Lick) the tide, although similarly small for the latitude, has roughly the normal phase with high tide after the moon's transits, an effect doubtless due to the presence of the great mountain chain of North and South America. Similar effects are, however, not shown by Kodaikanal and Periyakulam, in India, although the heights of those places differ more than do those of the American stations, the differences being as much as 2,249 metres. Equally remarkable is the practically world-wide retardation of the time of high tide in Lecember and January as compared with April or May, in spite of the fact that summer in one hemisphere corresponds with winter in the other. Work has been begun on the determination of the air currents of period equal to half a lunar day that must be associated with the pressure tide; this problem is being attacked with the aid of the long record available at Batavia.

\section{Ultra-Violet and Infra-Red Radiations on the Farm}

L. C. Porter, of the General Electric Company's incandescent lamp department in Cleveland, said, at a meeting of the American Society of Agricultural Engineers held on December 7, that if only electric current becomes cheap enough and suitable equipment is developed, then ultra-violet and infra-red radiations can have many uses on the electrified farm of the future (Science Service, Washington, D.C.). Adaptations of the familiar dull-red glowing electric heaters can readily be made for use in poultryhouses, in barns to keep new-born animals warm, and for the quick drying of hay. The greater com- pactness and decreased fire risk will give them considerable advantage over present types of equipment. Ultra-violet rays are known to have certain wellmarked physiological effects, as in activating sterols to produce vitamin $\mathrm{D}$ and in keeping in check the growth in length of plants. For producing wellproportioned plants in greenhouses, the use of a new kind of incandescent lamp is suggested which has a globe permeable to ultra-violet as well as to visible rays.

- With these and other lamps in proper proportions, a close approximation to natural sunlight can be obtained with control of duration and intensity not possible under natural conditions. The well-known germicidal effects of ultra-violet rays still await a number of possible practical applications on the farm. They may be used, for example, in dairies and stable buildings, as they now are in hospitals to keep down the germ population of the air. They may be called on to control the spread of epidemics among farm animals, and to check the growth of moulds and other fungi on hay, grain and other products. Their fluorescent effects may aid in diagnosing animal diseases and in examining vegetables and fruits. With Dr. Buttolph, physicist of the General Electric Company, Mr. Porter is publishing some of his suggestions in Agricultural Engineering.

\section{Helium Production in the United States}

THE developments of the last twenty years in helium production in the United States are described in Engineering of January 26. Reference is made to a lecture delivered recently in the College of Engineering of the University of Maryland by Dr. C. W. Siebel, supervising engineer of the Government-owned helium plant near Amarillo, Texas, and to a memorandum issued by the United States Bureau of Mines. The present helium-producing plant at Amarillo has a capacity of 24 million cubic feet of helium of 98.2 per cent purity a year, but it is stated in the Bureau of Mines memorandum that, by installing another production unit in existing buildings, the output could be raised to 36 million cubic feet a year. As the present military and commercial requirements, aggregating approximately 6 million cubic ft. a year, are met by operating the plant at about one quarter of the installed capacity, there is a large reserve for emergencies.

In addition to the Amarillo installation, the U.S. Government owns two smaller helium plants, at Dexter, Kansas, and at Thatcher, Colorado ; these are not being worked. They were built by private interests and purchased by the Government in 1937. To supply the Armarillo plant with helium-bearing natural gas, the Bureau of Mines has purchased all gas rights in 50,000 acres of land comprising the Cliffside gas field. It is stated that, on the basis of a conservative estimate, the Cliffside area contains at least 100,000 million cubic feet of natural gas having a helium content of 1.8 per cent. This is equivalent to a reserve of 1,800 million cubic feet of helium, or approximately two hundred times the 